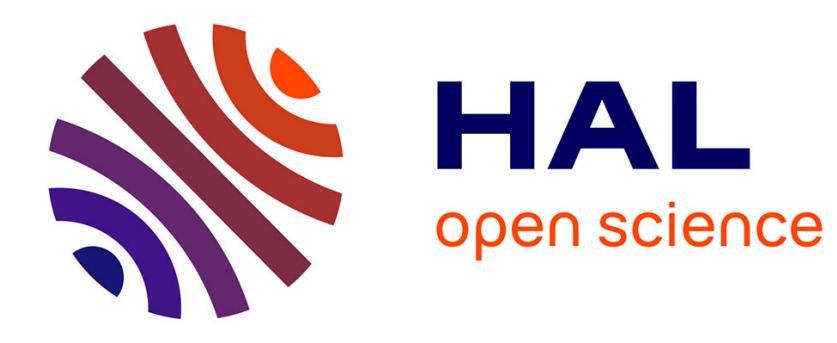

\title{
Health concepts at work in interdisciplinary fields
}

Jan Pieter Konsman

\section{To cite this version:}

Jan Pieter Konsman. Health concepts at work in interdisciplinary fields. Explaining Health Across the Sciences, pp.115-135, 2020, 10.1007/978-3- . hal-03041621

\section{HAL Id: hal-03041621 \\ https://hal.science/hal-03041621}

Submitted on 5 Dec 2020

HAL is a multi-disciplinary open access archive for the deposit and dissemination of scientific research documents, whether they are published or not. The documents may come from teaching and research institutions in France or abroad, or from public or private research centers.
L'archive ouverte pluridisciplinaire HAL, est destinée au dépôt et à la diffusion de documents scientifiques de niveau recherche, publiés ou non, émanant des établissements d'enseignement et de recherche français ou étrangers, des laboratoires publics ou privés. 
Konsman, J. P. (2020). Health concepts at work in interdisciplinary fields. In J. Scholl \& S. I. S. Rattan (Eds.), Explaining Health Across the Sciences (pp. 115-135). Cham: Springer-Nature. Doi: 10.1007/978-3030-52663-4_8

Published version available on https://link.springer.com/chapter/10.1007\%2F978-3-030-52663-4_8

\title{
Health concepts at work in interdisciplinary fields
}

\section{Jan Pieter Konsman}

Aquitaine Institute for Integrative and Cognitive Neuroscience, UMR CNRS 5287, University of Bordeaux, 146 rue Léo Saignat, 33076 Bordeaux, France

Phone / Fax: (33) 557571551 / (33) 556901421

Email: jan-pieter.konsman@u-bordeaux.fr

\begin{abstract}
Much of the debates surrounding the concepts of health in philosophy of medicine have been between 'naturalism' and 'normativism'. Here, the aim is to apply the revisionist naturalists' recommendation and to look for definitions of health in the biomedical literature. Based on our own research experience with neuroendocrinology, neuroimmunology, psychoneuroendocrinology, psychoneuroimmunology and microbiota-gut-brain research, we speculated that these interdisciplinary fields mobilize notions of health including: 1) health as constancy of internal milieu or homeostasis, 2) health as absence of or due to specific interoception, 3) health as absence of stress or as the result of eustress or hormesis, and 4) health as result of (immune) defense. To assess which health concepts interdisciplinary research fields studying interacting biological systems mobilize, the PubMed database was interrogated with search strings linking 1) proposed health concepts-related terms and biological systems, 2) health and health concepts-related terms, and 3) health and interdisciplinary research fields. Health was mostly encountered in the context of "health and disease" without being further specified. The terms stress, homeostasis and immune were most frequently used in relationship to health, but health was only clearly defined, referring to homeostasis, in two articles. More articles, however, evoked the biopsychosocial model of medicine in which "overall health reflects a high level of intra- and intersystemic harmony" (Engel, 1978, p. 175). In conclusion, applying the revisionist naturalists' recommendation to scrutinize the theoretical sense of 'health' throughout the
\end{abstract}


biomedical literature will need to go beyond the level of definitions and may therefore not be that straightforward.

\section{Keywords}

Bibliometrics, empirical philosophy of medicine and science, homeostasis, interdisciplinary biomedical research

\section{Concepts of health in philosophy of medicine}

According to the WHO, health is "a state of complete physical, mental, and social well-being and not merely the absence of disease or infirmity". Much of the debates surrounding the concepts of health and disease in philosophy of medicine have been between two poles that can be qualified as 'objectivism' or 'naturalism' and 'constructivism' or 'normativism'. In this debate, the former stipulates that health and disease can be objectively defined based on natural functioning of a body and the latter opposes that these notions depend primarily on values that social groups hold. Christopher Boorse, as the major proponent of naturalistic accounts, stated in 1977 that: "Health as freedom from disease is then statistical normality of function", which corresponds to "the ability to perform all typical physiological functions with at least typical efficiency" (Boorse, 1997, p. 542; p. 562). Twenty years later, he persistently argued that: "Theoretical health is the absence of disease" (Boorse, 1997, p. 1). Lennart Nordenfelt, instead, proposed a normative "holistic welfare" account of health according to which a person " $P$ is healthy, if and only if $P$ is able, given standard circumstances, to realise all his or her vital goals, i.e. to realise all those states of affairs which are necessary and together sufficient for his or her minimal happiness" (Nordenfelt, 1993, p. 172). If Boorse's naturalistic concept of health does not respect the spirit of the WHO definition of health, "Nordenfelt's definition of health is [just] less extensive than the WHO's conception" (Schramme, 2007, p. 14).

It may well be that, in spite of the still-ongoing debate between the two camps, "philosophy of medicine has reached an impasse over how to define the concepts of health and disease" (Sholl, 2015, pp. 395-396). Several paths forward have been indicated, ranging from calls for stronger holism considering "the individual as an integrated whole of organs and organ parts" as "an absolute condition for health in scientific medicine" (Taljedal, 2004, p. 145), or that "health and disease are best understood as systemic or organismic properties" (Sholl, 2015, p. 412), to a defense of a naturalist theory of health "taking account of the point of view of medical science" in addition to an individual's evaluation of his or her condition (Schramme, 2007, p. 15). In an effort to put, at least, a temporary hold on the debate around the notion of disease, revisionist naturalists have proposed to look "for perspicuous and coherent accounts of different disease types" and to finally come to "an overall picture of the role disease thinking plays" (Murphy, 2015). Maël Lemoine, another proponent of this stance, suggested that "[t]he philosopher's job is to scrutinize the theoretical sense of 'disease' throughout medical science and decide whether a consistent, specific, and operational concept of disease exists therein" (Lemoine, 2013, p. 324). In the present chapter, the aim is to try and apply Murphy's and Lemoine's recommendations to health and to look for definitions of health in the biomedical literature. 
Even though the WHO is very clear on what health is not, it is not easy to conceive how "a state of complete physical, mental, and social well-being" can be addressed by biomedical science. In addition, if one would like to follow the plea for holistic approaches in trying to understand health as 'systemic properties', one is faced with the problem that most medical and biological disciplines employ reductionist strategies. One may therefore be more likely to encounter health concepts that go beyond the absence of dysfunction or disease in interdisciplinary research fields that propose to span different biological systems and/or disciplines.

Over the past decades, some more holistic definitions of health have been put forward in medicine. In an article on medical education in 1950, John Romano, defined health as "the capacity of the organism to maintain a balance in which it may be reasonably free of undue pain, discomfort, disability or limitation of action, including social capacity" (Romano, 1950, p. 409). The internist and psychiatrist George Engel used this definition as a starting point but judged it too broad (Engel, 1960, p. 48). In the 1970s, Engel expressed the hope that "a general-systems approach becomes part of the basic scientific and philosophic education of future physicians and medical scientists" (Engel, 1977, p. 135) and proposed the biopsychosocial model of medicine. In addition, Engel specified that his model is based on Von Bertalanffy's general systems theory and stipulated that "overall health reflects a high level of intra- and intersystemic harmony" and that restoration of health "is not the former state of health but represents a different intersystemic harmony than existed before the illness" (Engel, 1978, pp. 175-176).

Recently, several authors have presented psychoneuroendocrinology, psychoneuroimmunology, and microbiota-gut-brain research as fields relevant to, or as validations of, the biopsychosocial model (Gaab, 2019; Havelka et al, 2009; Maier \& al'Absi, 2017; Morgan et al, 2014; Trilling, 2000). Here, the interdisciplinary research fields of neuroendocrinology, neuroimmunology, psychoneuroendocrinology, psychoneuroimmunology and microbiota-gut-brain research, which address in varying ways interactions between biological systems, including the nervous system, will be analyzed and compared for the concepts of health they mobilize. Based on our own research experience in and with these different fields of research, we speculate that they mobilize notions of health including: 1) health as constancy of internal milieu or homeostasis, 2) health as absence of or due to specific interoception, 3) health as absence of stress or as the result of eustress or hormesis, and 4) health as result of (immune) defense. Based on the assumptions and histories of these fields, we hypothesize in particular that neuroendocrinology would preferentially mobilize notion 1) and neuroimmunology and psychoneuroimmunology notion 4), while psychoneuroimmunology and psychoneuroimmunology may apply notion 3) more.

Health concepts that may be at work in interdisciplinary basic and medical research

1) Constancy internal milieu-homeostasis $\rightarrow$ health as a disposition to maintain vital parameters fixed or within normal range?

Claude Bernard proposed the stability of the internal milieu as the condition for life. With regard to health and disease, he pointed out in his Introduction to Experimental Medicine that "[b]y normal activity of its organic units, life exhibits a state of health; by abnormal manifestation of 
the same units, diseases are characterized" (Bernard, 1949, p. 65) and that "it is in the study of inner organic conditions that direct and true explanations are to be found for the phenomena of the life, health, sickness and death of the organism" (Bernard, 1949, p. 98). Walter Cannon was inspired by Bernard's work when he introduced the notion of homeostasis, but did not necessarily equate homeostasis to health. For example, he wrote regarding plasma proteins that: "The very existence of the fluid matrix of the body is dependent, therefore, on constancy of the proteins in the plasma-and usually they are remarkably constant in various conditions of health and disease" (Cannon, 1929, p. 412).

Even though Christopher Boorse considered that "the notion of homeostasis has wide ... influence as a clinical concept of health" (Boorse, 1977, p. 549) and that "[c]ountless biological variables like blood temperature, acidity, speed of flow, ... must be kept within narrow limits in a state of health" (Boorse, 1977, p. 549), he did not consider homeostasis "as a general model of biological function". Indeed, for Boorse "[m]any life functions", such as "[p]erception, locomotion, growth and reproduction upset an equilibrium" and can therefore not be qualified as "homeostatic unless one stretches the concept" (Boorse, 1977, p. 550).

More recently, Masseh Annath presented a philosophical account of health using homeostasis as a starting point. Indeed, his account includes "elements of homeostasis [that] are relevant to the various organs and organ systems of the body" as well as a notion of "organism homeostasis" (Ananth, 2008, pp. 191-193).

2) "Life lived in the silence of the organs" $\rightarrow$ health as result of specific interoception?

In the 1930s, the French surgeon Réné Leriche stipulated that "[h]ealth is life lived in the silence of the organs" (Leriche, 1936, p. 16). Recent research, in particular by Bud Craig, has identified neural afferents that have been proposed to convey the physiological condition of the body, a phenomenon called interoception (Craig, 2002). It is, however, important to point out that, in spite of the initial formulation of Leriche and the fact that an important part of interoceptionrelated research is on pain and/or inflammation, some authors have also emphasized the importance of internal health signals and feelings of wellness (Fantuzzi, 2014; Mayer, 2011). For example, Emeran Mayer proposed that a feeling of wellness may occur in response to the gut sensation or state of satiation (Mayer, 2011). In addition, Giamila Fantuzzi suggested that "we can approach biomedical research from the point of view of studying what improves health" and "define messages of health as molecules produced and released by healthy, unstressed cells and whose presence contributes to support a healthy organism“ (Fantuzzi, 2014, p. 1).

3) Stress response $\rightarrow$ health as lack of distress, or result of eustress or hormesis?

In the mid-20 ${ }^{\text {th }}$ century, Hans Selye raised the possibility that "many individuals who carry the pathogens (whatever these may be) of rheumatoid arthritis, allergies, lupus erythematosus, and so forth can remain in perfect health throughout life" because "they have rendered these potential pathogens quite innocuous" through "the general adaptation syndrome", which was later to become the stress response (Selye, 1950), p. 1388). In addition, he wondered what aspects of the stress response "are useful for the maintenance of health and which are merely signs of damage" (Selye, 1955, p. 626). Later in his career Selye proposed to distinguish "between 'eustress' and 'distress' - the former being agreeable or healthy, and the latter, disagreeable or 
pathogenic" depending on the "intensity [of a certain stimulus] and the particular receptiveness of the affected person" (Selye, 1976, p. 54).

Edward Calabrese and others have recently positioned hormesis as adaptive and protective responses to stressors and "defined [it] as a dose-response phenomenon characterized by a low dose stimulatory response and a high dose inhibition" (Calabrese, 2008, p. 9). In addition to its purely descriptive definition, "hormesis may [also] be defined on the basis of evolutionarily conserved biological responses to stress" (Hoffmann, 2009, p. 5) with the idea "that biological systems must routinely experience mild stress for optimization of health" (Hoffmann, 2009, p. 27).

4) Guardians of health $\rightarrow$ health as a result of (immune) defense?

Elie Metchnikoff reported at the end of the $19^{\text {th }}$ century that he has "succeeded ... in isolating infected Daphniae [water flea] and keeping them till they were fully restored to health, thanks to the destruction of the spores by their phagocytes" (Metchnikoff, 1893, p. 85). Later, he mentioned "recent discoveries" showing that "blood-serum of animals which have been subjected to the action either of microbes or of the soluble products of microbes ... is capable ... of protecting those in good health from diphtheria" (Metchnikoff, 1908, p. 211). Several decades later, Frank Macfarlane Burnet still considered that: "the phagocytic cells ... are the final defenders of the body" (Burnet, 1940, p. 36). Even in the early 1960s when humoral-specific immunity in the form of antibodies had eclipsed cellular immunity somewhat, Burnet made it clear again that "there are ... a variety of phenomena for which antibody plays no part" (Burnet, 1962, p. 42).

In the past decades, some scientists have proposed to move "from an antigen-centered, clonal perspective of immune responses to an organism-centered, network perspective of autonomous activity in a self-referential immune system (Coutinho et al, 1984, p. 151). Others have suggested that "the immune system [i]s but one component of a larger, integrated system of defenses serving the adaptive interests of the individual" (Ader, 2000). Most recently, the view that "the immune response [i]s an integral and dynamic part of how animals optimize their fitness in challenging, competitive environments" even has become the cornerstone of the emerging field of research of eco-immunology (Viney, 2014, p. 1).

\section{Methodology}

To assess which health concepts interdisciplinary research fields studying interacting biological systems mobilize, the biomedical literature database PubMed (https://www.ncbi.nlm.nih.gov/pubmed) was interrogated with search strings linking 1) proposed health concepts-related terms (homeostasis, interoception, stress, defense) and biological systems, 2) health and health concepts-related terms, and 3) health and interdisciplinary research fields. For searches undertaken to evaluate the penetration of health concepts-related terms in relation to biological systems, the relative (compared to the total amount of PubMed articles) numbers of publications per year were analyzed. In contrast, analyses pertaining to health and health concepts-related terms and to health and interdisciplinary research fields were more aimed at contents. Therefore, searches yielding more than 500 hits 
were repeated by adding more specific terms or "review" to the search string until the number of hits fell below 500. In this case, titles and abstracts were scrutinized and publications that were, at least, in part, conceptual were selected. In these articles, it was determined to what health and health-related terms refer.

\section{Results}

PubMed search strings associating proposed health concepts-related terms and biological systems Among the terms that may be employed in relation to health in articles found on PubMed, 'stress', 'homeostasis' and 'defense' were the most frequently encountered with 'stress' making up for $4 \%$ of the recently indexed articles and 'homeostasis' and 'defense' for respectively 1.15-1.20\% and $0.6 \%$. The percentage of PubMed articles obtained with the search string "( (nervous and endocrine) or neuroendocrine) and homeostasis" was found to increase fourfold between 1953 and 2000-2018, while that for "((nervous and immune) or neuroimmune) and homeostasis" rose tenfold from 1980 to 2018 (Fig. 1A). Similarly, a tenfold increase in the percentage of PubMed articles in which 'stress' was associated with the adjectives nervous and endocrine or the compound adjective neuroendocrine was observed between 1961 and 2000-2018 (Fig. 1B). Regarding 'defense', steady increases in the percentage of PubMed articles between the 1970s and 2018 were found for the search strings "((nervous and endocrine) or neuroendocrine) and defense" and "((nervous and immune) or neuroimmune) and defense", fluctuating around 0.02\% and $0.0035 \%$ in the past years, respectively (Fig. 1C). Finally, search strings combining 'interocept*' with the adjectives nervous, immune and immune or compound adjectives like neuroendocrine or neuroimmune yielded too few hits to do any meaningful quantitative analyses on. 
A: Homeostasis \& compound + combined adjectives

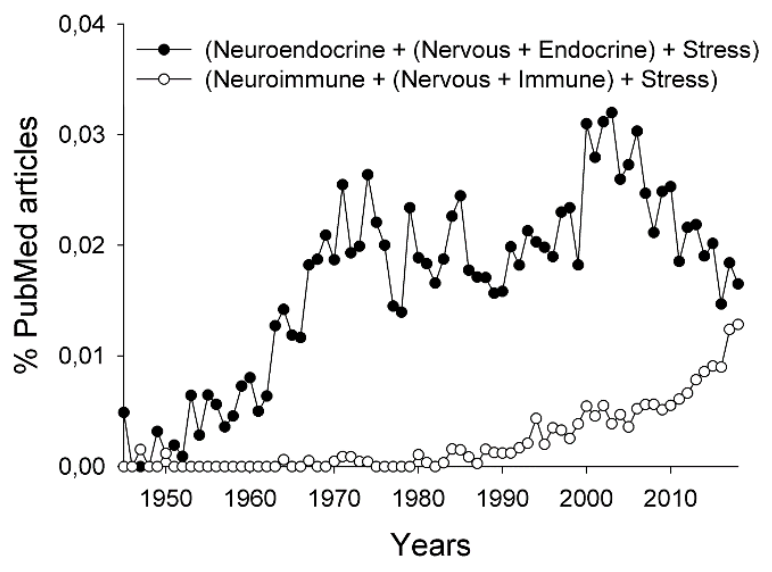

B: Stress \& compound + combined adjectives

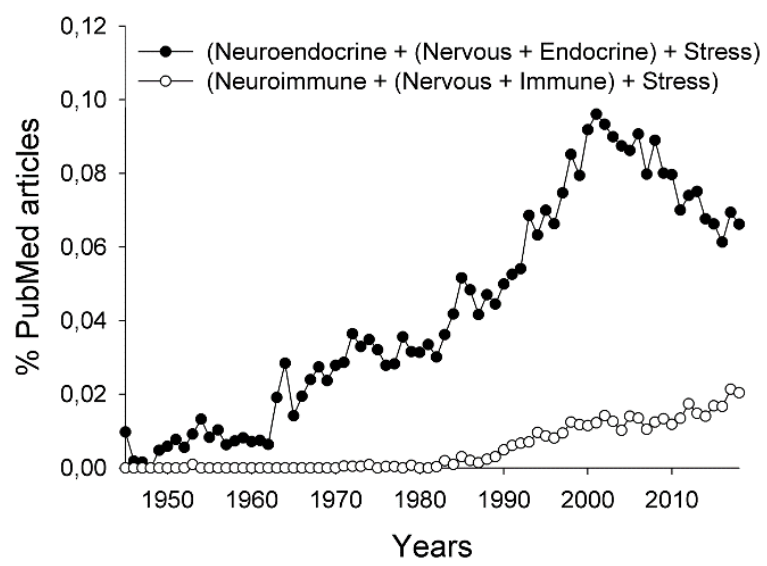

C: Defense \& compound + combined adjectives

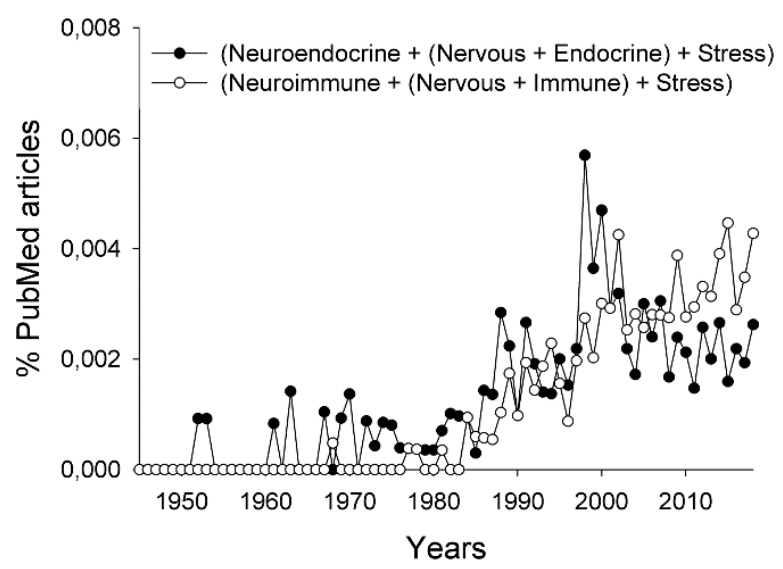

Figure 1, Konsman 
PubMed search strings linking health and proposed health concepts-related terms

The majority of the articles obtained with the search strings with health and health conceptsrelated terms in their titles referred to "health and disease".

Homeostasis and health

Several of 137 PubMed articles with homeostasis and health in their titles did not concern the organism, system, or tissue level and were therefore not considered. Two conceptual articles were found (Table 1). G. N. Kryzhanovsky's judged that "satisfactory definitions of ... health and disease, have not been found for a long time" and proposed that "[f]or comprehensive consideration of the problem and definition of the notions 'health' and 'disease', it is necessary to dwell on ... homeostasis" (Kryzhanovsky, 2004, p. 135). Concerning homeostasis, he emphasized that "it is reasonable to consider dynamic, functional homeostasis rather than a strictly rigid one" (Kryzhanovsky, 2004, p. 136). This then brought Kryzhanovsky to define health as "the state of an organism with undisturbed functional dynamic homeostasis providing optimum performance of organism functions to the extent necessary for productive relations of the organism with the environment" (Kryzhanovsky, 2004, p. 137).

Antoine Dussault and Anne-Marie Gagné-Julien suggested "that an organism's health is linked to its ability to homeostatically maintain the functions of its organs and its whole body" (Dussault \& Gagne-Julien, 2015, p. 69). However, they considered that "homeostatic maintenance, although necessary, is not sufficient for health" and "that an account of health should include a reference to a design", which is grounded "in ontogeny rather than phylogeny" (Dussault \& Gagne-Julien, 2015, p. 72). Thus, Dussault and Gagné-Julien proposed their "homeostatic maintenance of design (HHMD)" definition of health according to which "[a]n organism is healthy if and only if it is intrinsically disposed to homeostatically maintain or restore its intrinsic disposition to perform its designed functions in relevant situations" (Dussault \& Gagne-Julien, 2015, p. 75).

\section{Interoception and health}

Several of the 9 PubMed articles with interocept* and health in their titles addressed conceptual issues (Table 1). Depending on the authors, interoception was proposed to include "the process of receiving, accessing and appraising internal bodily signals" (Farb et al, 2015, p. 1), "reflexes, urges, feelings, drives, adaptive responses, and cognitive and emotional experiences" (Khalsa et al, 2018, p. 501) and "(1) the afferent (body-to-brain) [neural and humoral] signaling ...; (2) the neural encoding, representation, and integration of this information ...; (3) the influence of such information on other perceptions, cognitions, and behaviors; (4) and the psychological expression of these representations" (Quadt et al, 2018, p. 112).

Well-being was often encountered with statements like "interoception is critical for our sense of embodiment, motivation, and wellbeing" (Farb et al, 2015, p. 1) or "[a] comprehensive understanding of cognition, emotion, and overall well-being must incorporate an understanding of interoception" (Quadt et al, 2018, p. 112). However, well-being was not described beyond "physical and mental well-being" (Quadt et al, 2018, p. 112). Likewise, health was also not further specified other than that "[h]ealth and disease have distinct ... profiles that can be characterized by the presence or absence of reported symptoms and changes in behavior" (Quadt et al, 2018, p. 119). Although the majority of PubMed articles with interocept* and health in their titles 
referred to mental health, a closer inspection revealed that these articles dealt with mental health problems and disorders (Farb et al, 2015; Khalsa et al, 2018; Tsakiris, 2018).

\section{Stress or hormesis and health}

Some of the 427 PubMed review articles with stress and health in their titles referred to health professionals, economics or heat stress and were not considered. Several conceptual articles on stress and health were found (Table 1) of which many spent some ink on the problem of the definition of stress (Edwards \& Cooper, 1988; Kasl, 1984; Korte et al, 2005; McEwen, 2008). This naturally led to calls "to define stress cleanly" (Kasl, 1984, p. 320), to "separately assess individuals' perceptions of events ... appraisal ... health-related outcomes, and coping efforts" (Edwards \& Cooper, 1988, p. 15) or to adopt "a new stress concept" such as allostasis or allostatic load (Korte et al, 2005; McEwen, 2008).

With regard to health, the vast majority of these articles contained formulations like "stress-related changes have broad implications for health" (Glaser \& Kiecolt-Glaser, 2005, p. 248) or "[s]tress ... can take its toll on physical and mental health" (Korte et al, 2005, p. 4), but none provided a definition of health. Some authors also discussed the notion "that some stress may be seen as 'good', with corresponding health status benefits" before criticizing the idea "that some levels (or types) of stress are associated with health benefits" and recommending that "such issues need to be argued out on an empirical basis and with more specific and precise concepts" (Kasl, 1984, p. 321, pp. 322-323). Others have argued that "certain aspects of the stress and coping process may actually improve health" (Edwards \& Cooper, 1988, p. 18).

Some of the 25 PubMed review articles with hormesis and health in their titles were more conceptual in nature (Table 1). The basic idea behind the so-called "hormesis hypothesis" would be the "existence of hidden defense capacities which become activated in response to 'mild" stresses", which, in turn, "enhance [the] organisms' robustness and resilience properties" (Yashin, 2009, p. 41). Accordingly, some authors stated that some naturally occurring "stressors ... are required for healthy growth or homeostasis" and claims that this "exemplifies how "illness is the doorway to health'” (Li et al, 2019, p. 944). But like for stress, none of these more conceptual reviews containing health and hormesis in their titles provided a definition or description of health.

\section{Immune and health}

Many of the 307 articles with defense and health in their titles referred to national or department of defense, psychological defense, defense of some point of view or policy or public health. None of them seemed to address conceptual issues regarding defense or health. Many of the 371 PubMed review articles with immun* and health in their titles were on immunization, immunizing or immuno(histo)chem*, health care or health professionals and were excluded. Some articles linked immun* and mental health and these also made up the majority of the more conceptual articles (Table 1).

Among the conceptual articles, only one dealt with the immune system as such and concerned the description of "the properties of trained immunity", and proposed to discuss "its important role in health and disease" (Netea et al, 2016, p. aff1098-1, p. aaf1098-7). The other three publications addressed the role of the immune system as part of a network of interacting biological systems in mental health. Thus, Jaclyn Schwarz "hypothesize[d] that interactions 
between the endocrine, immune and nervous system of mother and infant have an important impact on the risk of ... psychiatric disorders" and expressed her motivation "to ... prevent the onset of mental health disorders in the mother" (Schwarz, 2019, pp. 1-2, p. 4). The two articles by Chris Stapelberg and colleagues dealt with changes in "the psycho-immunoneuroendocrine [PNIE] network" relevant to the transition "from health to major depression" (Stapelberg et al, 2019; Stapelberg et al, 2018). Thus, these papers proposed hypotheses "constructed around a model of disease progression wherein the stable healthy state of the PINE network undergoes progressive but reversible pathophysiological changes to an unstable pre-disease state", but also explored how the "PINE network may then undergo critical transition to a stable, possibly irreversible disease state of [major depressive disorder] MDD" (Stapelberg et al, 2019, p. 108). However, none of these more conceptual articles provided a definition or a description of (mental) health.

PubMed search strings associating health and interdisciplinary research fields

Neuroendocrinology and health

Several of the 40 publications obtained with the search string "health [TI] AND neuroendocrinology" were already encountered under stress and health. A relatively high proportion of conceptual articles was found, with several being written by Bruce McEwen's group (Table 1).

The first of the selected articles by McEwen proposed to "summarize our current knowledge of glucocorticoid physiology in relation to immune function in health and disease" (McEwen et al, 1997, p. 80). Subsequent publications by this group put forward the concepts of allostasis and allostatic load. These concepts were introduced with regard to "physical and mental health" considering the "profound effects" of the "stability of a child's early life" (McEwen, 2003, p. 149). Allostatic load can be "defined as the 'cost' or 'wear and tear' on the body produced by repeated activation of stress-responsive biological mediators such as glucocorticoids and catecholamines" (McEwen, 2003, p. 149). "These stress processes impacting health can be heuristically labeled as 'good', 'tolerable', and 'toxic' - depending on the degree to which an individual has control over a given stressor and has support systems and resources in place for handling a given stressor over the lifespan" (McEwen \& Gianaros, 2010, p. 190).

Other authors also tried to differentiate between the detrimental and beneficial effects of stressful situations on health. For example, Courtney DeVries writes that "[i]n contrast to social stress and social isolation, positive social interactions are beneficial to health" (DeVries et al, 2007 , p. 588). Still other authors pointed out that "the association between chronic daily stress and anxiety and poor physical health" may be mediated through "neuroimmune and neuroendocrine responses" and that "[m]indfulness-based interventions exert positive impacts on an individual's mental health in addition to physical health" (Beerse et al, 2019, p. 2). But despite the fact physical and mental health are regularly mentioned, these terms are never defined.

\section{Neuroimmunology and health}

Two articles of the 29 obtained with health as a title word and neuroimmunology dealt with more conceptual issues (Table 1).

In 1996, Hymie Anisman and colleagues claimed that "[a] novel scientific discipline that examines the complex interdependence of the neural, endocrine and immune systems in health 
and disease has emerged in recent years" (Anisman et al, 1996, p. 867). Thus, it was hypothesized that "[t]he immune system is constantly interacting with the neuroendocrine system" and that " $[t]$ his interaction assures that immune and inflammatory responses are in homeostasis and in harmony with other bodily functions, in order to maintain health" (Anisman et al, 1996, pp. 868869).

A more recent article by Michal Schwartz and colleagues focused on "[h]ow ... immune cells support and shape the brain in health" (Schwartz et al, 2013, p. 17587). Besides, the role of "[m]icroglia and infiltrating monocyte-derived macrophages ... in maintenance of brain plasticity in health" (Schwartz et al., J. Neurosci., 2013, p. 17587), these authors indicated that "CNS-specific T cells are involved in the maintenance of the functional plasticity of the healthy brain" (Schwartz et al, 2013, pp. 17588-17589). Accordingly, neuroimmunology "is a field in which the two systems not only interact but also have a mutual dependency" (Schwartz et al, 2013, p. 17593). However, and in spite of describing in some detail what neuroimmunology is in the context of health, health is never defined in these publications.

\section{Psychoneuroendocrinology and health}

Of the 68 articles obtained with health as a title word and psychoneuroendocrinology, several were more conceptual (Table 1). Some of these publications were already encountered under stress and health.

In 1983, John Money argued that "[a] psychoendocrine rapprochement began to appear in the 1950s" when "Geoffrey W. Harris (1913-71) moved toward psychology and behavior" and the author "moved psychology and behavior toward endocrinology" (Money, 1983, p. 394). Several authors discussed the links between stress, health and psychoneuroendocrinology as well as psychoneuroimmunology (Kelly et al, 1997; Vitetta et al, 2005, p. 494). For example, Vitetta and colleagues concluded, based on "evidence ... accumulate[d] within the field of psychoneuroendocrinology and psychoneuroimmunology", that "the brain has truly an overarching role in health and disease" (Vitetta et al, 2005, p. 502).

The paper from Bruce McEwen's group reviewed "theoretical and empirical work using the allostatic load model vis-à-vis the effects of chronic stress on physical and mental health" (Juster et al, 2010, p. 2). Thus, Robert-Paul Juster and colleagues stated that "[h]ealth and successful aging can ... be conceptualized as one's ability to adapt and effectively respond to the dynamic challenges of being alive" (Juster et al, 2010, p. 2). In contrast to the "[t]raditional homeostatic models [that] define health as a state in which all physiological parameters operate within normal values", "allostasis defines health as a state of responsiveness and optimal predictive fluctuation to adapt to the demands of the environment" (Juster et al, 2010, pp. 2-3). Accordingly, "[a]llostasis differs from homeostasis vis-à-vis its emphasis on dynamic rather than static biological set-points, considerations of the brain's role in feedback regulation, and view of health as a whole-body adaptation to contexts" (Juster et al, 2010, p. 3).

So, among the more conceptual/theoretic articles found here, several described what psychoneuroendocrinology is about and one article even provided a definition of health that does not refer to homeostasis. 


\section{Psychoneuroimmunology and health}

Searching PubMed for health as a title word and psychoneuroimmunology yielded 105 articles, of which numerous were more conceptual (Table 1). Several articles were already encountered under stress and health.

Many of these conceptual articles addressed the health psychology question of "why do some people get sick and others stay well". Thus, in 1994, Nancy Adler and Karen Matthews noted that "the psychology community has increasingly embraced questions of essential importance to physical health" (Adler \& Matthews, 1994, p. 230) and hypothesized regarding the health outcomes of stress, that "appraisal of stress appears to play a more important role ... than simple exposure to life events" (Adler \& Matthews, 1994, p. 251). A year later, Janice Kiecolt-Glaser and Ronald Glaser suggested "that immune modulation by psychosocial stressors and/or interventions may importantly influence health status," in particular in "those whose immune system function is already compromised to some degree" (Kiecolt-Glaser \& Glaser, 1995, p. 269). Sheldon Cohen and Tracy Herbert argued that "[m]uch of psychoneuroimmunology's popularity ... derives from its promise to explore and explain the common belief that our personalities and emotions influence our health" (Cohen \& Herbert, 1996, p. 114), but also warned that "immune ... outcomes ... do not necessarily indicate changes in resistance to disease" (Cohen \& Herbert, 1996, p. 117).

In the early 2000s, Susan Lutgendorf and Erin Constanzo considered that "[p]sychoneuroimmunology provides an understanding of some of the fundamental mechanisms involved in the biopsychosocial model" (Lutgendorf \& Costanzo, 2003, p. 225), but also pointed out that "[i]t cannot be assumed that because there is an effect on the immune response there is also an effect on disease processes" (Lutgendorf \& Costanzo, 2003, p. 231). Mladen Havelka and colleagues agreed that "[t]he biopsychosocial model" has given rise to "the fields of health psychology and psychoneuroimmunology" (Havelka et al, 2009, p. 303), but added that "[Engel] also claims that the borderline between disease and health has never been clear" (Havelka et al, 2009 , p. 305). Robert Zachariae put forward a slightly different story in suggesting that "[b]y challenging the biomedical concept of the immune system as an 'autonomous' defense system, psychoneuroimmunology represents a shift from a predominantly biomedical paradigm of health and disease towards an interdisciplinary bio-psycho-social approach" (Zachariae, 2009, p. 645). He did, however, agree that "the critical question of whether behavioral manipulation, e.g. stressors or intervention, can affect immunity so as to influence health and survival, still remained to be answered" (Zachariae, 2009, p. 650).

In spite of the regular reference to health, only one of the more conceptual articles mentioning psychoneuroimmunology proposes a definition. Thus, Nancy McCain and colleagues "broadly define health to include the entire spectrum of wellness-illness phenomena" and considered that "the [PNI] model incorporates a variety of health outcomes, termed 'adaptational outcomes' includ[ing] psychosocial functioning, quality of life, and physical health" (McCain et al, 2005, p. 323).

\section{Microbiota gut brain research and health}

Of the 8 articles obtained with the search string "health [TI] AND "microbiome gut brain"”, one more conceptual article dealing with mental health was found (Table 1). In this article, Grace 
Lucas argued that "if ... the gut is "an organ of mind" this raised the questions of "[w]hat and where exactly is our 'mental' health?" (Lucas, 2018, p. 2). She referred to a definition of "[m]ental health ... framed within a biopsychosocial paradigm", but judged that "despite its emphasis on an integration of perspectives, [this paradigm] speaks to disciplinary boundaries of biology, psychology, and social sciences" with "each taking a vertical disciplinary cut through the mental health conundrum" (Lucas, 2018, pp. 4-5). Lucas also related how "[p]roponents of alternative models of health may reach to microbiome-gut-brain research to validate why it is necessary to think holistically about health", but warned that "data connecting the gut to mood, behaviour and mental health does not provide a neat answer" (Lucas, 2018, p. 6). Nevertheless, she acknowledged as an upshot of this research that "it does call attention to the possibilities for a model of 'embodied mental health' ..., one that recognises that mental health is not a separate entity from physical health and explores the entanglements within a horizontal bio-psychosocial framework" (Lucas, 2018, p. 6) without providing an explicit definition of health.

\section{Discussion}

The overall conclusion of our investigations on how "health" is employed in articles available on the biomedical literature database PubMed is that in the vast majority of cases the term is encountered in the context of "health and disease" without being further specified. In these cases, the disease part is often developed whereas health is not. Among the terms that we proposed may be employed in relation to health in articles found on PubMed, stress, homeostasis and defense were the most frequently encountered with stress recently making up for $4 \%$ of the indexed articles. When using these terms and health as title words, by far the most hits were obtained for "health and stress" and "health and immun*", even when limited to reviews. However, many reviews containing health and immun* in their titles concerned immunization, immunizing or immuno(histo)chem*, health care or health professionals. Three of the four more conceptual articles found with "health and immun*" were on mental health (Schwarz, 2019; Stapelberg et al, 2019; Stapelberg et al, 2018), but none provided a definition or a description of (mental) health. Comparatively, more reviews with health and stress in their titles dealt with conceptual issues. These issues often concerned the problem of the definition of stress or the nature of the effects of stress on health, but none provide a definition or description of health.

Using homeostasis and health as title words resulted in more than a hundred publications on PubMed, of which two were judged more conceptual. Interestingly, these did not only contain further specifications of the concept of homeostasis, but also proposed definitions of health that both referred to an organism's function. Thus, Kryzhanovsky defined health as "the state of an organism with undisturbed functional dynamic homeostasis providing optimum performance of organism functions to the extent necessary for productive relations of the organism with the environment" (Kryzhanovsky, 2004, p. 137). Dussault and Gagné-Julien proposed their "homeostatic maintenance of design (HHMD)" definition of health according to which "[a]n organism is healthy if and only if it is intrinsically disposed to homeostatically maintain or restore its intrinsic disposition to perform its designed functions in relevant situations" (Dussault \& Gagne-Julien, 2015, p. 75). The differences in style of formulation between these two definitions may be related to the fact that Kryzhanovsky is a scientist and Dussault and Gagné-Julien are 
philosophers. Even though interocept* and health as title words only rendered 9 articles, many of these were conceptual in nature. Moreover, it is noteworthy in light of the WHO definition of health, which refers to well-being, that interoception in these articles was often linked to wellbeing. For example, statements like "interoception is critical for our sense of embodiment, motivation, and wellbeing" (Farb et al, 2015, p. 1) and "[a] comprehensive understanding of cognition, emotion, and overall well-being must incorporate an understanding of interoception" (Quadt et al, 2018, p. 112) were found. However, in none of these instances were well-being and health described beyond physical and mental well-being or health.

We speculated that one may be more likely to encounter health concepts that go beyond the absence of dysfunction or disease in studies that propose to span different biological systems, including the nervous system, or different biomedical disciplines. We therefore also investigated the occurrence of the terms mentioned above in the context of possible interactions between biological systems. Interestingly, the percentages of PubMed articles obtained with the search strings associating homeostasis, stress or defense on the one hand, and (nervous and endocrine) or neuroendocrine) or (nervous and immune) or neuroimmune) on the other, all increased 4-10 fold between 1946 and 2018. To address the question of how interdisciplinary research fields studying interacting biological systems use the term health, we employed searches employing "health" as a title word in association with neuroendocrinology, neuroimmunology, psychoneuroendocrinology, psychoneuroimmunology or microbiota-gut-brain research. Although very few of the conceptual articles thus found defined health, an important proportion referred to the biopsychosocial model, stress and interacting biological systems. In particular, Robert-Paul Juster and colleagues proposed that in contrast to "[t]raditional homeostatic models defin[ing] health as a state in which all physiological parameters operate within normal values", "allostasis defines health as a state of responsiveness and optimal predictive fluctuation to adapt to the demands of the environment" (Juster et al, 2010, pp. 2-3).

We postulated that neuroendocrinology would preferentially mobilize notions of health involving homeostasis, neuroimmunology and psychoneuroimmunology would rely on notions of health referring to defense, while psychoneuroendocrinology and psychoneuroimmunology would apply stress-related notions. Based on our analysis of the relevant biomedical literature, it appeared that homeostatic health accounts were found in all of these domains if only as a starting point to criticize. Referring to stress in the context of health was also not limited to psychoneuroendocrinology and psychoneuroimmunology, but also found in neuroendocrinology. Alternatively, this raises the question of how tight the borders are between neuroendocrinology and neuroimmunology, on the one hand, and psychoneuroendocrinology and psychoneuroimmunology, on the other.

Taken together, our findings indicate that, even though health was rarely explicitly defined in the publications identified with our search strings, the few that did so all use homeostasis as a starting point. Many more articles referred to the biopsychosocial model of medicine in the context of which George Engel stated that "overall health reflects a high level of intra- and intersystemic harmony" (Engel, 1978, p. 175). Still more publications seemed to establish links between health and stress. However, while the vagueness of the concept may have facilitated more integrative models, it has the potential to render the links between stress and health more 
complicated between some forms of stress having negative health consequences and other forms of stress promoting health.

So, if one would like to apply the recommendation to base a concept of disease on "accounts of different disease types" (Murphy, 2015); https://plato.stanford.edu/entries/healthdisease/) or "to scrutinize the theoretical sense of 'disease' throughout medical science and decide whether a consistent, specific, and operational concept of disease exists" (Lemoine, 2013, p. 324) to the notion of health, this is likely not going to be straightforward. First, and possibly in contrast to disease, which covers different types, and for which it may therefore be conceivable to come up with a common theoretical sense, the notion of health is not supposed to exist in different forms, except for the broad division into mental and physical health. This being said, notions of health referring to parts of the organism, such as "brain health" or "healthy microbiota", are increasingly being encountered in the biomedical literature. But in these cases it still concerns one health state and many more possible disease states for the same part. Second, the different disease types have at least rather precise diagnostic criteria to start with, whereas notions of health seem to lack such criteria. Beyond diagnostic criteria, there is an increased interest in biomarkers. Even though most of the literature concerns biomarkers of disease, the idea of biomarkers of health is getting some traction. Related to the notions of health discussed, Giamila Fantuzzi seemed to allude to biomarkers of health when she "define[d] messages of health as molecules produced and released by healthy, unstressed cells and whose presence contributes to support a healthy organism" (Fantuzzi, 2014, p. 1). However, it is not straightforward to image a marker of something like health that is not clearly defined to start with. In addition, and like for biomarkers of disease, there will also be the question of specificity of a biomarker of health. Finally, based on our investigation of part of the biomedical literature, it appears that health is most often considered as the opposite of disease and that even when some notions of health are hypothesized to be linked to defense, homeostasis or stress, few clear descriptions are encountered. While the lack of conceptual clarity may be problematic for philosophy of biology and medicine, that does not seem to be the case for science, for which it may even allow for establishing new links and working hypotheses.

\section{References}

Ader, R. (2000) On the development of psychoneuroimmunology. Eur J Pharmacol, 405(1-3), 16776.

Adler, N. \& Matthews, K. (1994) Health psychology: why do some people get sick and some stay well? Annu Rev Psychol, 45, 229-59.

Ananth, M. (2008) In defense of an evolutionary concept of health. Nature, norms, and human biology. Farnham: Ashgate.

Anisman, H., Baines, M. G., Berczi, I., Bernstein, C. N., Blennerhassett, M. G., Gorczynski, R. M., Greenberg, A. H., Kisil, F. T., Mathison, R. D., Nagy, E., Nance, D. M., Perdue, M. H., Pomerantz, D. K., Sabbadini, E. R., Stanisz, A. \& Warrington, R. J. (1996) Neuroimmune mechanisms in health and disease: 1. Health. CMAJ, 155(7), 867-74. 
Beerse, M. E., Van Lith, T., Pickett, S. M. \& Stanwood, G. D. (2019) Biobehavioral utility of mindfulness-based art therapy: Neurobiological underpinnings and mental health impacts. Exp Biol Med (Maywood), 1535370219883634.

Bernard, C. (1949) Introduction to the study of experimental medicine. New York: Henry Schuman. Boorse, C. (1977) Health as a theoretical concept. Philosophy of Science, 44(4), 542-573.

Boorse, C. (1997) A rebuttal on health, in Humber, J. M. \& Almeder, R. F. (eds), What is Disease?Humana Press, 1--134.

Briones, T. L. (2007) Psychoneuroimmunology and related mechanisms in understanding health disparities in vulnerable populations. Annu Rev Nurs Res, 25, 219-56.

Brosschot, J. F., Gerin, W. \& Thayer, J. F. (2006) The perseverative cognition hypothesis: a review of worry, prolonged stress-related physiological activation, and health. J Psychosom Res, 60(2), 113-24.

Burnet, F. M. (1940) Biological aspects of infectious disease. Cambridge: Cambridge University of Press.

Burnet, F. M. (1962) The integrity of the body: a discussion of modern immunological ideas Cambridge: Harvard University Press.

Calabrese, E. J. (2008) Converging concepts: adaptive response, preconditioning, and the YerkesDodson Law are manifestations of hormesis. Ageing Res Rev, 7(1), 8-20.

Calabrese, E. J., lavicoli, I. \& Calabrese, V. (2013) Hormesis: its impact on medicine and health. Hum Exp Toxicol, 32(2), 120-52.

Cannon, W. B. (1929) Organization for Physiological Homeostasis. Physiol Rev, 9(3), 399-431.

Cohen, J. I. (2000) Stress and mental health: a biobehavioral perspective. Issues Ment Health Nurs, 21(2), 185-202.

Cohen, S. \& Herbert, T. B. (1996) Health psychology: psychological factors and physical disease from the perspective of human psychoneuroimmunology. Annu Rev Psychol, 47, 113-42.

Coutinho, A., Forni, L., Holmberg, D., Ivars, F. \& Vaz, N. (1984) From an antigen-centered, clonal perspective of immune responses to an organism-centered, network perspective of autonomous activity in a self-referential immune system. Immunol Rev, 79, 151-68.

Craig, A. D. (2002) How do you feel? Interoception: the sense of the physiological condition of the body. Nat Rev Neurosci, 3(8), 655-66.

DeVries, A. C., Craft, T. K., Glasper, E. R., Neigh, G. N. \& Alexander, J. K. (2007) 2006 Curt P. Richter award winner: Social influences on stress responses and health. Psychoneuroendocrinology, 32(6), 587-603.

Dussault, A. C. \& Gagne-Julien, A. M. (2015) Health, homeostasis, and the situation-specificity of normality. Theor Med Bioeth, 36(1), 61-81.

Edwards, J. R. \& Cooper, C. L. (1988) Research in stress, coping, and health: theoretical and methodological issues. Psychol Med, 18(1), 15-20.

Engel, G. L. (1960) A unified concept of health and disease. IRE Trans Med Electron, ME-7, 48-57. Engel, G. L. (1977) The need for a new medical model: a challenge for biomedicine. Science, 196(4286), 129-36.

Engel, G. L. (1978) The biopsychosocial model and the education of health professionals. Ann $N Y$ Acad Sci, 310, 169-87.

Eriksen, H. R., Olff, M., Murison, R. \& Ursin, H. (1999) The time dimension in stress responses: relevance for survival and health. Psychiatry Res, 85(1), 39-50. 
Fantuzzi, G. (2014) The sound of health. Front Immunol, 5, 351.

Farb, N., Daubenmier, J., Price, C. J., Gard, T., Kerr, C., Dunn, B. D., Klein, A. C., Paulus, M. P. \& Mehling, W. E. (2015) Interoception, contemplative practice, and health. Front Psychol, 6, 763.

Gaab, J. (2019) The placebo and its effects: a psychoneuroendocrinological perspective. Psychoneuroendocrinology, 105, 3-8.

Glaser, R. \& Kiecolt-Glaser, J. K. (2005) Stress-induced immune dysfunction: implications for health. Nat Rev Immunol, 5(3), 243-51.

Havelka, M., Lucanin, J. D. \& Lucanin, D. (2009) Biopsychosocial model--the integrated approach to health and disease. Coll Antropol, 33(1), 303-10.

Hoffmann, G. R. (2009) A perspective on the scientific, philosophical, and policy dimensions of hormesis. Dose Response, 7(1), 1-51.

Juster, R. P., McEwen, B. S. \& Lupien, S. J. (2010) Allostatic load biomarkers of chronic stress and impact on health and cognition. Neurosci Biobehav Rev, 35(1), 2-16.

Kasl, S. V. (1984) Stress and health. Annu Rev Public Health, 5, 319-41.

Kelly, S., Hertzman, C. \& Daniels, M. (1997) Searching for the biological pathways between stress and health. Annu Rev Public Health, 18, 437-62.

Khalsa, S. S., Adolphs, R., Cameron, O. G., Critchley, H. D., Davenport, P. W., Feinstein, J. S., Feusner, J. D., Garfinkel, S. N., Lane, R. D., Mehling, W. E., Meuret, A. E., Nemeroff, C. B., Oppenheimer, S., Petzschner, F. H., Pollatos, O., Rhudy, J. L., Schramm, L. P., Simmons, W. K., Stein, M. B., Stephan, K. E., Van den Bergh, O., Van Diest, I., von Leupoldt, A., Paulus, M. P. \& Interoception Summit, p. (2018) Interoception and Mental Health: A Roadmap. Biol Psychiatry Cogn Neurosci Neuroimaging, 3(6), 501-513.

Kiecolt-Glaser, J. K. \& Glaser, R. (1995) Psychoneuroimmunology and health consequences: data and shared mechanisms. Psychosom Med, 57(3), 269-74.

Korte, S. M., Koolhaas, J. M., Wingfield, J. C. \& McEwen, B. S. (2005) The Darwinian concept of stress: benefits of allostasis and costs of allostatic load and the trade-offs in health and disease. Neurosci Biobehav Rev, 29(1), 3-38.

Kryzhanovsky, G. N. (2004) Some categories of general pathology and biology: health, disease, homeostasis, sanogenesis, adaptation, immunity New approaches and notions. Pathophysiology, 11(3), 135-138.

Lambert, K. G. (2005) The clinical neuroscience course: viewing mental health from neurobiological perspectives. J Undergrad Neurosci Educ, 3(2), A42-52.

Langley, P., Fonseca, J. \& Iphofen, R. (2006) Psychoneuroimmunology and health from a nursing perspective. Br J Nurs, 15(20), 1126-9.

Lemoine, M. (2013) Defining disease beyond conceptual analysis: an analysis of conceptual analysis in philosophy of medicine. Theor Med Bioeth, 34(4), 309-25.

Leriche, R. (1936) De la santé à la maladie, Encyclopédie française, 6.16.

Li, X., Yang, T. \& Sun, Z. (2019) Hormesis in Health and Chronic Diseases. Trends Endocrinol Metab, 30(12), 944-958.

Lucas, G. (2018) Gut thinking: the gut microbiome and mental health beyond the head. Microb Ecol Health Dis, 29(2), 1548250.

Lutgendorf, S. K. \& Costanzo, E. S. (2003) Psychoneuroimmunology and health psychology: an integrative model. Brain Behav Immun, 17(4), 225-32. 
Maier, K. J. \& al'Absi, M. (2017) Toward a Biopsychosocial Ecology of the Human Microbiome, Brain-Gut Axis, and Health. Psychosom Med, 79(8), 947-957.

Mayer, E. A. (2011) Gut feelings: the emerging biology of gut-brain communication. Nat Rev Neurosci, 12(8), 453-66.

McCain, N. L., Gray, D. P., Walter, J. M. \& Robins, J. (2005) Implementing a comprehensive approach to the study of health dynamics using the psychoneuroimmunology paradigm. ANS Adv Nurs Sci, 28(4), 320-32.

McEwen, B. S. (2003) Early life influences on life-long patterns of behavior and health. Ment Retard Dev Disabil Res Rev, 9(3), 149-54.

McEwen, B. S. (2008) Central effects of stress hormones in health and disease: Understanding the protective and damaging effects of stress and stress mediators. Eur J Pharmacol, 583(2-3), 17485.

McEwen, B. S., Biron, C. A., Brunson, K. W., Bulloch, K., Chambers, W. H., Dhabhar, F. S., Goldfarb, R. H., Kitson, R. P., Miller, A. H., Spencer, R. L. \& Weiss, J. M. (1997) The role of adrenocorticoids as modulators of immune function in health and disease: neural, endocrine and immune interactions. Brain Res Brain Res Rev, 23(1-2), 79-133.

McEwen, B. S. \& Gianaros, P. J. (2010) Central role of the brain in stress and adaptation: links to socioeconomic status, health, and disease. Ann N Y Acad Sci, 1186, 190-222.

Metchnikoff, E. (1893) Lectures on the Comparative Pathology of Inflammation. London: Kegan \& Co.

Metchnikoff, E. (1908) The Nature of Man: Studies in Optimistic Philosophy. New York \& London: Putnam's sons.

Miller, G., Chen, E. \& Cole, S. W. (2009) Health psychology: developing biologically plausible models linking the social world and physical health. Annu Rev Psychol, 60, 501-24.

Money, J. (1983) The genealogical descent of sexual psychoneuroendocrinology from sex and health theory: the eighteenth to the twentieth centuries. Psychoneuroendocrinology, 8(4), 391400.

Morgan, N., Irwin, M. R., Chung, M. \& Wang, C. (2014) The effects of mind-body therapies on the immune system: meta-analysis. PLoS One, 9(7), e100903.

Murphy, D. (2015) Concepts of Disease and Health, 2015. Available online: https://plato.stanford.edu/entries/health-disease/

Netea, M. G., Joosten, L. A., Latz, E., Mills, K. H., Natoli, G., Stunnenberg, H. G., O'Neill, L. A. \& Xavier, R. J. (2016) Trained immunity: A program of innate immune memory in health and disease. Science, 352(6284), aaf1098.

Nordenfelt, L. (1993) Quality of Life, Health and Happiness. Aldershot: Avebury.

Quadt, L., Critchley, H. D. \& Garfinkel, S. N. (2018) The neurobiology of interoception in health and disease. Ann N Y Acad Sci, 1428(1), 112-128.

Roger, D. (1998) Stress, health and personality: a new perspective. Complement Ther Nurs Midwifery, 4(2), 50-3.

Romano, J. (1950) Basic orientation and education of the medical student. J Am Med Assoc, 143(5), 409-12.

Schneiderman, N., Ironson, G. \& Siegel, S. D. (2005) Stress and health: psychological, behavioral, and biological determinants. Annu Rev Clin Psychol, 1, 607-28. 
Schramme, T. (2007) A qualified defence of a naturalist theory of health. Med Health Care Philos, 10(1), 11-7; discussion 29-32.

Schwartz, M., Kipnis, J., Rivest, S. \& Prat, A. (2013) How do immune cells support and shape the brain in health, disease, and aging? J Neurosci, 33(45), 17587-96.

Schwarz, J. M. (2019) Frank Beach Award Winner - The future of mental health research: Examining the interactions of the immune, endocrine and nervous systems between mother and infant and how they affect mental health. Horm Behav, 114, 104521.

Selye, H. (1950) Stress and the general adaptation syndrome. Br Med J, 1(4667), 1383-92.

Selye, H. (1955) Stress and disease. Science, 122(3171), 625-31.

Selye, H. (1976) Forty years of stress research: principal remaining problems and misconceptions. Can Med Assoc J, 115(1), 53-6.

Sholl, J. (2015) Escaping the Conceptual Analysis Straitjacket: Pathological Mechanisms and Canguilhem's Biological Philosophy. Perspect Biol Med, 58(4), 395-418.

Stapelberg, N. J. C., Neumann, D. L., Shum, D. \& Headrick, J. P. (2019) Health, pre-disease and critical transition to disease in the psycho-immune-neuroendocrine network: Are there distinct states in the progression from health to major depressive disorder? Physiol Behav, 198, 108-119. Stapelberg, N. J. C., Pratt, R., Neumann, D. L., Shum, D. H. K., Brandis, S., Muthukkumarasamy, V., Stantic, B., Blumenstein, M. \& Headrick, J. P. (2018) From feedback loop transitions to biomarkers in the psycho-immune-neuroendocrine network: Detecting the critical transition from health to major depression. Neurosci Biobehav Rev, 90, 1-15.

Taljedal, I. B. (2004) Strong holism, weak holism, and health. Med Health Care Philos, 7(2), 143-8; discussion 149-52.

Taylor, S. E., Lerner, J. S., Sage, R. M., Lehman, B. J. \& Seeman, T. E. (2004) Early environment, emotions, responses to stress, and health. J Pers, 72(6), 1365-93.

Trilling, J. S. (2000) Selections from current literature. Psychoneuroimmunology: validation of the biopsychosocial model. Fam Pract, 17(1), 90-3.

Tsakiris, M. \& Critchley, H. (2016) Interoception beyond homeostasis: affect, cognition and mental health. Philos Trans R Soc Lond B Biol Sci, 371(1708).

Tsakiris, M., De Preester, H. (2018) The Interoceptive Mind: From Homeostasis to Awareness. Oxford: Oxford University Press.

Ursin, H. \& Eriksen, H. (2007) Cognitive activation theory of stress, sensitization, and common health complaints. Ann N Y Acad Sci, 1113, 304-10.

Viney, M. E. R., E. M. (2014) From Immunology to Eco-immunology: More than a New Name, in Malagoli D.; Ottaviani, E. (ed), Eco-immunology: Evolutive Aspects and Future Perpectives. Dordrecht, Heidelber, New York, London: Springer, 1-20.

Vitetta, L., Anton, B., Cortizo, F. \& Sali, A. (2005) Mind-body medicine: stress and its impact on overall health and longevity. Ann N Y Acad Sci, 1057, 492-505.

Yashin, A. I. (2009) Hormesis against aging and diseases: using properties of biological adaptation for health and survival improvement. Dose Response, 8(1), 41-7.

Zachariae, R. (2009) Psychoneuroimmunology: a bio-psycho-social approach to health and disease. Scand J Psychol, 50(6), 645-51. 
Table 1. Pubmed articles addressing conceptual issues regarding health and proposed healthrelated terms or health and interdisciplinary research fields (searches done during the first half of December 2019).

\begin{tabular}{|c|c|c|}
\hline Search string & Hits & References addressing conceptual issues \\
\hline Homeosta* [TI] AND health [TI] & 137 & (Dussault \& Gagne-Julien, 2015; Kryzhanovsky, 2004) \\
\hline Interocept* [TI] AND health [TI] & 9 & $\begin{array}{l}\text { (Farb et al, 2015; Khalsa et al, 2018; Quadt et al, 2018; Tsakiris } \\
\text { \& Critchley, 2016) }\end{array}$ \\
\hline $\begin{array}{l}\text { Stress }[\mathrm{TI}] \text { AND health }[\mathrm{TI}] \text { AND } \\
\text { review }\end{array}$ & 427 & $\begin{array}{l}\text { (Brosschot et al, 2006; Cohen, 2000; Edwards \& Cooper, 1988; } \\
\text { Eriksen et al, 1999; Glaser \& Kiecolt-Glaser, 2005; Kasl, 1984; } \\
\text { Korte et al, 2005; McEwen, 2008; Roger, 1998; Schneiderman } \\
\text { et al, 2005; Taylor et al, 2004; Ursin \& Eriksen, 2007; Vitetta } \\
\text { et al, 2005) }\end{array}$ \\
\hline Hormesis [TI] AND health [TI] & 25 & (Calabrese et al, 2013; Li et al, 2019; Yashin, 2009) \\
\hline Defense [TI] AND health [TI] & 307 & \\
\hline $\begin{array}{l}\text { Immun* }[\mathrm{TI}] \text { AND health }[\mathrm{TI}] \\
\text { AND review }\end{array}$ & 371 & $\begin{array}{l}\text { (Netea et al, 2016; Schwarz, 2019; Stapelberg et al, 2019; } \\
\text { Stapelberg et al, 2018) }\end{array}$ \\
\hline $\begin{array}{l}\text { Health }[\mathrm{TI}] \text { AND } \\
\text { neuroendocrinology }\end{array}$ & 40 & $\begin{array}{l}\text { (Beerse et al, 2019; DeVries et al, 2007; McEwen, 2003; 2008; } \\
\text { McEwen et al, 1997; McEwen \& Gianaros, 2010) }\end{array}$ \\
\hline $\begin{array}{l}\text { Health }[\mathrm{TI}] \text { AND } \\
\text { neuroimmunology }\end{array}$ & 29 & (Anisman et al, 1996; Schwartz et al, 2013) \\
\hline $\begin{array}{l}\text { Health [TI] AND } \\
\text { psychoneuroendocrinology }\end{array}$ & 68 & $\begin{array}{l}\text { (Juster et al, 2010; Kelly et al, 1997; Money, 1983; Vitetta et } \\
\text { al, 2005) }\end{array}$ \\
\hline $\begin{array}{l}\text { Health [TI] AND } \\
\text { psychoneuroimmunology }\end{array}$ & 105 & $\begin{array}{l}\text { (Adler \& Matthews, 1994; Briones, 2007; Cohen \& Herbert, } \\
\text { 1996; Glaser \& Kiecolt-Glaser, 2005; Havelka et al, 2009; } \\
\text { Kiecolt-Glaser \& Glaser, 1995; Lambert, 2005; Langley et al, } \\
\text { 2006; Lutgendorf \& Costanzo, 2003; McCain et al, 2005; Miller } \\
\text { et al, 2009; Zachariae, 2009) }\end{array}$ \\
\hline $\begin{array}{l}\text { health [TI] AND "microbiome } \\
\text { gut brain" }\end{array}$ & 8 & (Lucas, 2018) \\
\hline
\end{tabular}

